\title{
EFEITOS DA INTERCEPTAÇÃO LUMINOSA OU PERÍODO DE DESCANSO FIXO NO ACÚMULO DE FORRAGEM E ESTRUTURA DO DOSSEL DE UMA ANTIGA CULTIVAR DE Megathyrsus maximus
}

\author{
Philipe Lima de Amorim¹, Erica Laura Guilherme Lopes ${ }^{1}$, Andressa Mirielle Silva Moreira', Filipe Souza \\ Cavalcante', Guilherme Bastos Lyra', José Teodorico de Araújo Filho', Ana Iris Silva Santos ${ }^{1}$, Braulio \\ Maia de Lana Sousa ${ }^{2}$
}

\begin{abstract}
1 Universidade Federal de Alagoas, Campus de Engenharias e Ciências Agrárias, BR 104 Norte, Km 85, Rio Largo, Alagoas, 57100-000
2Universidade Federal de Sergipe, Departamento de Zootecnia, Avenida Marechal Rondon, S/N, São Cristovão, Sergipe, $49100-000$
\end{abstract}

*Autor para correspondência: Philipe Lima de Amorim; philipe.amorim@ceca.ufal.br

RESUMO: Objetivou-se com esse trabalho avaliar os efeitos frequência de colheita de pastos de Megathyrsus maximus cv. sempre-verde na estrutura, dinâmica do perfilhamento, período de descanso e ciclos de colheita. Foram avaliados três tratamentos, caracterizados por frequências de colheita, sendo elas: a de períodos fixos de 28 dias, sempre que dossel interceptasse $90 \%$ ou $95 \%$ da luz incidente, seguindo delineamento inteiramente casualizado com quatro repetições. Houve efeito das frequências de colheita na altura do dossel, índice de área foliar e interceptação luminosa tanto na pré-colheita quanto pós-colheita. A taxa de aparecimento de perfilhos foi maior nos pastos manejados a $90 \%$ de interceptação luminosa do que quando manejados a períodos fixos de 28 dias. Efeito inverso foi observado na taxa de sobrevivência de perfilhos, em que os pastos manejados a períodos de 28 dias apresentaram maior média do que aqueles a $90 \%$ de interceptação luminosa. Maior número de ciclos de colheita e menor período de descanso foram observados na frequência de $90 \%$ de interceptação luminosa e menores no período fixo de descanso. Não houve influência das frequências na massa de forragem, porcentagem de colmo vivo, forragem morta, acúmulo de forragem e taxa de acúmulo de forragem. Observou-se efeito das frequências apenas na porcentagem de lâminas foliares, em que a frequência de $90 \%$ de interceptação luminosa apresentou o maior valor médio. A correlação entre a interceptação luminosa ou índice de área foliar com a altura do dossel apresentou-se forte e positiva. A utilização da frequência de colheita variável é mais efetiva em controlar a estrutura do dossel que a fixa, além de proporcionar foragem de composição morfológica mais adequada ao consumo animal e perfil mais jovem da população de perfilhos. 0 capim sempre-verde pode ter sua rebrotação interrompida quando o dossel atingir entre $80-85 \mathrm{~cm}$ de altura e o pastejo encerrado quando atingir $50 \mathrm{~cm}$.

PALAVRAS CHAVE: ambiente luminoso, capim-sempre-verde, frequência de colheita, Panicum maximum, período de descanso.

\section{EFFECTS OF LIGHT INTERCEPTION OR FIXED REST PERIOD ON FORAGE ACCUMULATION AND CANOPY STRUCTURE OF AN ANCIENT CULTIVAR OF Megathyrsus maximus}

ABSTRACT: The objective of this work was to evaluate the frequency effects of pasture harvest of Megathyrsus maximus cv. Sempre-verde in structure, tillering dynamics, rest period and harvest cycles. Three treatments, characterized by harvesting frequencies, were evaluated: fixed periods of 28 days, whenever the canopy intersected $90 \%$ or $95 \%$ of the incident light, following a completely randomized design with four replications. There were effects of harvesting frequencies on canopy height, leaf area index and light interception both pre-harvest and post-harvest. Tiller emergence rate was higher in pastures managed at $90 \%$ light interception than when managed at fixed periods of 28 days. An inverse effect was observed on tiller survival rate, where pastures managed at 28day periods presented higher average than those at $90 \%$ light interception. Higher number of harvesting cycles and shorter rest period were observed at $90 \%$ frequency of light interception and shorter in the fixed rest period. There was no influence of frequencies on forage mass, percentage of live stem, dead forage, forage accumulation and rate of forage accumulation. The effect of frequencies was only observed on the percentage of leaf blades, 
where the $90 \%$ frequency of light interception presented the highest mean value. The correlation between light interception or leaf area index with canopy height was strong and positive. The use of variable harvesting frequency is more effective in controlling the canopy structure than the fixed one, besides providing forage of morphological composition more adequate to animal consumption and younger profile of tillers population. Sempre-verde grass may have your regrowth stopped when the canopy reaches $80-85 \mathrm{~cm}$ in height and grazing is over when it reaches $50 \mathrm{~cm}$

KEY WORDS: havest frequency, light environment, Panicum maximum, rest period, Sempre-verde grass.

\section{INTRODUÇÃO}

As gramíneas do gênero Megathyrsus (Syn. Panicum) são as mais produtivas forrageiras tropicais propagadas por sementes, apresentando alta produtividade de folhas, porte elevado, bom valor nutricional e alta aceitabilidade pelos animais, proporcionando bom desempenho aos animais quando em manejadas (Jank et al., 2010). A Megathyrsus maximus cv. Sempre Verde (capim Sempre-verde) é pouco difundida no Brasil, sendo mais encontrada no Norte de Minas Gerais e regiões mais úmidas dos estados da Bahia e Alagoas. É originada da África, sendo considerada adaptação do capim-colonião ( $M$. maximus cv. Colonião) às adversidades de clima e solo. Em comparação ao capim Colonião, possui colmos mais finos, folhas mais estreitas e porte menor, apresentando coloração verde-amarelada. É perene, rústica, resistente à seca (daí sua denominação sempre-verde), devido a reservas que são acumuladas em bulbos na base da touceira. Apresenta média exigência em fertilidade de solo, com maior tolerância ao alumínio que o capim Colonião (Jank et al., 2010).

Historicamente, o capim Sempre-verde tem sido manejado por meio de práticas generalistas, utilizando períodos de descanso fixos e que não levam em consideração as características morfofisiológicas e respostas da cultivar ao meio em que está inserida. Essas ações de manejo repercutem em um sucesso limitado dos sistemas produtivos, com menor produção e perda da qualidade da forragem, havendo, desse modo, maior acúmulo de colmos e forragem morta, bem como redução no consumo e desempenho dos animais (Macedo et al., 2010; Da Silva \& Nascimento Jr., 2007).

A adoção do período de descanso utilizando o critério da interceptação luminosa (IL) implica na utilização de períodos de descansos variáveis, de acordo com as modificações da taxa de crescimento do pasto. Devido está técnica apresentar elevada relação com a altura do dossel forrageiro, a mesma pode ser utilizada como técnica-guia para monitorar e manejar o processo de pastejo (Carnevalli et al. 2006).

0 manejo é um importante condicionador da estrutura do dossel forrageiro. Assim, o estudo do mesmo com base no critério da interceptação luminosa (IL) associado à altura do dossel (AD), dentre outras características estruturais, contribuem efetivamente para o aumento o conhecimento sobre os fatores limitantes e de desenvolvimento das espécies (Pompeu et al., 2009). A determinação de metas mais adequadas de manejo para o capim Sempre-verde podem torná-lo uma alternativa viável para diversificação de pastagens e para aumentar a produtividade da pecuária. Neste sentido, objetivou-se avaliar os efeitos frequência de colheita de pastos de Megathyrsus maximus cv. Sempre-verde sobre o acúmulo de forragem e estrutura do pasto.

\section{MATERIAL E MÉTODOS}

\section{Local do estudo, tratamentos e delineamento experimental}

0 trabalho foi realizado no Centro de Ciências Agrárias (CECA) da Universidade Federal de Alagoas, localizado no município de Rio Largo, Zona da Mata Alagoana, no período de abril de 2017 a março de 2018. O município situa-se a $9^{\circ} 27^{\prime}$ de latitude sul e $35^{\circ} 27^{\prime}$ de longitude oeste e $127 \mathrm{~m}$ de altitude. As informações referentes às condições climáticas durante o período experimental podem ser observadas na Tabela 1.

Previamente à implantação do experimento, amostras de solo foram retiradas na profundidade de 0 a $20 \mathrm{~cm}$, para análise das suas características químicas. Foram registrados os seguintes valores: $\mathrm{pH}$ (água) - 5,8; $\mathrm{P}\left(\mathrm{mg} \mathrm{dm}^{-3}\right)-4$; $\mathrm{k}\left(\mathrm{mg} \mathrm{dm}^{-3}\right)$ - 39; $\mathrm{Ca}+$ $\mathrm{Mg}\left(\mathrm{mg} \mathrm{dm}^{-3}\right)-3,4 ; \mathrm{Al}\left(\mathrm{mg} \mathrm{dm}^{-3}\right)-0,12 ; \mathrm{H}+\mathrm{Al}(\mathrm{mmolc}$ $\left.d^{-3}\right)-57 ; V(\%)-38,9$; CTC efetiva - 3,75; Matéria orgânica (\%) - 2,97. 
Tabela 1. Resultado mensal das variáveis meteorológicas durante o período experimental

\begin{tabular}{lcccccc}
\hline \multirow{2}{*}{ Mês/ano } & \multicolumn{5}{c}{ Variáveis meteorológicas } \\
\cline { 2 - 7 } & Tméd & Tmáx & Tmín & Irradiação & Umidade & Precipitação \\
\hline abr/17 & 25,7 & 31,6 & 21,3 & 18,4 & 78,9 & 168,1 \\
mai/17 & 24,6 & 33,3 & 21,0 & 14,6 & 83,6 & 584,7 \\
jun/17 & 23,5 & 29,0 & 19,7 & 13,6 & 85,1 & 477,8 \\
jul/17 & 22,0 & 27,1 & 17,0 & 12,8 & 84,6 & 418,1 \\
ago/17 & 22,5 & 29,1 & 18,1 & 16,7 & 83,3 & 154,9 \\
set/17 & 22,8 & 28,3 & 17,6 & 19,6 & 80,6 & 120,1 \\
out/17 & 24,0 & 30,1 & 18,9 & 21,1 & 78,2 & 37,1 \\
nov/17 & 25,0 & 32,9 & 19,2 & 23,3 & 74,7 & 14,2 \\
dez/17 & 25,8 & 34,5 & 20,1 & 22,4 & 74,2 & 69,3 \\
jan/18 & 25,6 & 33,1 & 20,7 & 22,1 & 76,5 & 119,4 \\
fev/18 & 25,8 & 32,0 & 21,3 & 20,4 & 78,5 & 137,7 \\
Média & 24,4 & 34,5 & 17,0 & 18,7 & 79,6 & $2.301,4^{*}$ \\
\hline
\end{tabular}

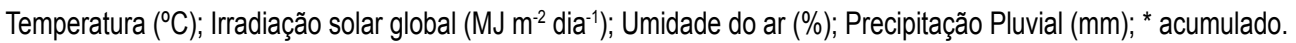

Foram avaliados três tratamentos, caracterizados por frequências de colheita da planta forrageira: período fixo de 28 dias (28D), sempre que dossel interceptasse $90 \%$ (90IL) ou $95 \%$ (95IL) da luz incidente. 0 delineamento experimental utilizado foi 0 inteiramente casualizado, com quatro repetições.

A área experimental foi preparada pelo método convencional (aração e gradagem do solo) em março de 2017. Em abril do mesmo ano, para o plantio, foram retiradas mudas do capim-sempre verde, em área adjacente, procurando-se selecionar touceiras jovens e em estádio vegetativo. Posteriormente a retirada, as parcelas foram delimitadas $(2 \times 2 \mathrm{~m})$ e as mudas foram plantadas em covas, utilizando-se o espaçamento de 0,5 $\times 0,5 \mathrm{~m}$. No momento do plantio das mudas, foram aplicados um equivalente a 10 tha ${ }^{-1}$ de esterco ovino $(1,85 \% \mathrm{~N}, 0,44 \%$ P2O5, 0,6\% K20 e 32,6\% de matéria orgânica) sobre a superfície do solo. Aos 15 dias após plantio, aplicou-se 70 $\mathrm{kg} \mathrm{ha}^{-1}$ de nitrogênio, a lanço, na forma de ureia. No início de agosto foi realizada mais uma adubação com $70 \mathrm{~kg}$ ha $^{-1}$ de nitrogênio, na forma de ureia, juntamente com 50 $\mathrm{kg} \mathrm{ha}^{-1}$ de $\mathrm{P}_{2} \mathrm{O}_{5}$ e $\mathrm{K}_{2} \mathrm{O}$, nas formas de superfosfato simples e cloreto de potássio, respectivamente.

Trinta dias após o plantio (final de maio), realizou-se um corte de uniformização em todas as parcelas experimentais, a aproximadamente $30 \mathrm{~cm}$ de altura do solo. Posteriormente a uniformização, todas as parcelas foram manejadas segundo as três condições de desfolhação 28D, 90IL ou 95IL. Assim, quando os dosséis forrageiros atingiam as respectivas condições de intervalo entre cortes, esses foram colhidos por meio de corte manual com auxílio de foices. Para uniformizar a intensidade de corte, a altura residual, condição pós-corte (POC), correspondeu a $40 \%$ da altura do dossel na condição de pré-corte (PRC) para todos os tratamentos (Fonseca et al., 2012).

\section{Mensurações no pasto}

Durante todo o período experimental, a altura do dossel (AD) nas parcelas foi monitorada de forma concomitante com a interceptação de luz pelo dossel forrageiro. Aaltura foi medida em seis pontos aleatórios, por unidade experimental. Cada ponto correspondeu à altura média da curvatura das folhas superiores em torno de uma régua graduada em centímetros (Bathram, 1985). A altura do dossel por unidade experimental correspondeu à média das seis leituras.

Para avaliação da interceptação de luz (IL) e do índice de área foliar (IAF) do dossel forrageiro, foi utilizado o aparelho analisador de dossel LAI-2000 (LICOR). As leituras foram tomadas seguindo-se as recomendações de uso do aparelho. Em cada unidade experimental foram avaliadas seis estações de leitura, sendo cada estação composta por uma medição acima do dossel forrageiro e 5 medições no nível do solo (abaixo do dossel). Em todos os tratamentos foram registrados, antes e depois da colheita (PRC e POC), a altura do dossel, interceptação luminosa e índice de área foliar. Realizou-se a correlação entre a interceptação luminosa, altura do dossel e índice de área foliar. Os coeficientes de correlação de Pearson (r) foram gerados a partir do banco de dados de todos os tratamentos $(n=200)$. 
A dinâmica de perfilhamento foi avaliada em duas touceiras por parcela, onde todos os perfilhos foram contados e identificados. A cada 28 dias, durante todo o período experimental, o processo de identificação e contagem de perfilhos foi repetido nas mesmas touceiras, sendo os novos perfilhos marcados com fios coloridos de uma nova cor. A partir dos dados colhidos, foram calculadas as taxas de aparecimento (TAP), mortalidade (TMP), balanço entre morte e aparecimento de perfilhos (BAL), sobrevivência (TSP) e índice de estabilidade (IE) da população de perfilhos basilares de acordo com as seguintes fórmulas: Taxa de aparecimento $=\left[n^{0}\right.$ de perfilhos novos (última geração marcada) $] x$ $100 / n^{\circ}$ de perfilhos totais existentes (gerações marcados anteriores); Taxa de mortalidade $=$ (perfilhos marcados anteriores - perfilhos sobreviventes) $\times 100 / n^{0}$ total de perfilhos na marcação anterior; Balanço entre morte e aparecimento de perfilhos = TAP - TMP; Taxa de sobrevivência $=\left(n^{0}\right.$ de perfilhos da marcação anterior vivos na marcação atual $\times 100) / n^{0}$ de perfilhos vivos na marcação anterior. Índice de estabilidade da população de perfilhos $=$ TSP $(1+T A P)$.

Todas as vezes que os dosséis atingiam suas respectivas frequências, duas amostras de forragem foram colhidas (quadrados de 0,5 x 0,5 m) por unidade experimental. Os cortes foram realizados manualmente com o auxílio de foices. As amostras foram divididas em duas subamostras: uma foi usada para estimar a massa de forragem (MF) e a outra foi separada em lâmina foliar (LF), colmo vivo (CV) e forragem morta (FM) de modo a estimar a porcentagem desses componentes na massa de forragem. Através do somatório das massas de forragem, subtraindo-se a quantidade de forragem morta, calculou-se o acúmulo de forragem (AF). A taxa de acúmulo de forragem (TAF) e taxa de acúmulo de lâminas foliares (TALF) foi estimada dividindo-se 0 acúmulo de forragem e lâminas foliares por seus respectivos períodos de descanso.

\section{Análises estatísticas}

Os dados relativos à altura do dossel, interceptação luminosa e índice de área foliar foram agrupados e analisados nas condições PRC e POC. Os dados da dinâmica do perfilhamento, número de ciclos e período de descanso não foram agrupados dessa forma e são provenientes de média de todo período experimental. As variáveis foram submetidas a análise de variância, tendo as médias entre os tratamentos comparadas pela Tukey a $10 \%$ de probabilidade para o erro tipo I.

\section{RESULTADOS}

\section{Altura do dossel, interceptação luminosa e índice de área foliar}

Foi observado, na AD de PRC, que a frequência de 28D apresentou maior média $(104,61 \mathrm{~cm})$, com menores valores $(P<0,0001)$ sendo observados nos tratamentos de 90IL e 95IL $(80,46$ e $85,27 \mathrm{~cm}$, respectivamente) (Tabela 2). De forma semelhante à $A D$ no $P R C$, na $A D$ no $P O C$, frequência de $28 D$ também apresentou o maior valor médio $(63,19 \mathrm{~cm})$, com as frequências de 90IL e 95IL não diferindo entre si.

Tabela 2. Altura do dossel, interceptação luminosa e índice de área foliar na condição de pré e pós-corte do capimsempre verde submetido a frequências de colheita

\begin{tabular}{|c|c|c|c|c|c|}
\hline \multirow{2}{*}{ Variável } & \multicolumn{3}{|c|}{ Frequências de colheita } & \multirow[b]{2}{*}{ CV $(\%)^{1}$} & \multirow[b]{2}{*}{ P-valor } \\
\hline & $90 I \mathrm{~L}$ & $95 \mathrm{IL}$ & $28 \mathrm{D}$ & & \\
\hline \multicolumn{6}{|c|}{ Pré-corte } \\
\hline Altura do dossel & $80,46 b$ & $85,27 b$ & $104,61 \mathrm{a}$ & 4,44 & $<0,0001$ \\
\hline Interceptação luminosa & $90,83 \mathrm{~b}$ & $94,72 \mathrm{a}$ & 95,81 a & 1,31 & 0,0007 \\
\hline Índice de área foliar & $3,37 \mathrm{c}$ & $3,79 \mathrm{~b}$ & $4,15 a$ & 4,85 & 0,0007 \\
\hline \multicolumn{6}{|c|}{ Pós-corte } \\
\hline Altura do dossel & $48,37 \mathrm{~b}$ & $51,87 \mathrm{~b}$ & $63,19 a$ & 4,4 & $<0,0001$ \\
\hline Interceptação luminosa & $74,48 \mathrm{~b}$ & $67,74 \mathrm{c}$ & $81,63 \mathrm{a}$ & 4,48 & 0,0008 \\
\hline Índice de área foliar & $1,49 b$ & $1,66 \mathrm{~b}$ & $2,03 a$ & 10,6 & 0,0007 \\
\hline
\end{tabular}

${ }^{1} \mathrm{CV}$ : coeficiente de variação.

AIL, na condição de PRC, apresentou diferenças entre os tratamentos $(P=0,0007)$, com maiores valores médios sendo observados nas frequências de $28 \mathrm{D}$
$(95,81 \%)$ e $95 \mathrm{IL}(94,72 \%)$ e menor em $90 \mathrm{IL}(90,83 \%)$ (Tabela 2). Na IL POC, a frequência de 28D apresentou o maior $(P=0,0008)$ valor $(81,63 \%)$, com 0 tratamento 
de 90IL apresentando valores intermediários $(74,48 \%)$ e menores na frequência de 95IL $(67,74 \%)$.

O IAF na condição de PRC, apresentou diferença ( $P=0,0007)$ entre os tratamentos, em que a 28D apresentou maior valor $(4,13)$, a $95 \mathrm{IL}$ apresentou valor intermediário $(3,79)$ e o tratamento 90IL apresentou o menor valor $(3,37)$ (Tabela 2). De modo semelhante ao IAF PRC, o maior IAF POC foi observado ( $P=0,0007)$ na frequência $28 D(2,03)$, sendo os tratamentos manejados por IL, semelhantes $(1,46 \mathrm{e}$ 1,66 para 90IL e 95IL, respectivamente).

\section{Número de ciclos e período de descanso}

$\mathrm{O}$ número de ciclos de corte $(\mathrm{NC})$ e período de descanso (PD) durante todo período experimental foram influenciados $(P<0,0001)$ pelas frequências de colheita (Tabela 3 ). 0 capim-sempre verde manejado na frequência de $90 \mathrm{IL}$ apresentou maior número de ciclos de corte $(11,75)$ e menor período de descanso (22,47 dias) do que aqueles manejados a $95 \mathrm{IL}(9,75$ cortes e 28,15 dias $)$ e $28 \mathrm{D}$ ( 9 cortes e 28 dias).

Tabela 3. Número de ciclos de corte e período de descanso (dias) de pastos de capim Sempre-verde submetidos a frequências de colheita

\begin{tabular}{lcccccc}
\hline \multirow{2}{*}{ Variáveis } & \multicolumn{3}{c}{ Frequências de colheita } & & \multirow{2}{*}{ CV (\%) ${ }^{1}$} & P-valor \\
\cline { 2 - 5 } & $90 \mathrm{IL}$ & $95 \mathrm{IL}$ & $28 \mathrm{D}$ & & \\
\hline Número de ciclos de corte & $11,75 \mathrm{a}$ & $9,75 \mathrm{~b}$ & $9,0 \mathrm{~b}$ & & 6,13 & 0,0001 \\
Período de descanso (dias) & $22,47 \mathrm{a}$ & $28,15 \mathrm{~b}$ & $28,0 \mathrm{~b}$ & & 4,39 & 0,0001 \\
\hline
\end{tabular}

${ }^{1} \mathrm{CV}$ : coeficiente de variação.

\section{Dinâmica do perfilhamento}

Com relação ao perfilhamento, observou-se diferenças apenas na TAP $(P=0,049)$ e TSP $(P=0,043)$. A TMP, BAL, IE e DPP não sofreram efeito dos tratamentos (Tabela 4). A TAP foi maior quando os pastos foram manejados na frequência de $90 \mathrm{IL}(0,58)$ e menores com período de descanso de $28 \mathrm{D}(0,40)$. De forma inversa a TAP, a TSP foi maior nos pastos manejados na frequência de $28 \mathrm{D}(0,80)$ e menores na de 90IL $(0,67)$, com 95IL apresentando valores intermediários $(0,77)$.

Tabela 4. Variáveis descritoras do perfilhamento e densidade populacional de perfilhos de pastos de capim Sempre-verde submetidos a frequências de colheita

\begin{tabular}{lccccc}
\hline \multirow{2}{*}{ Variáveis } & \multicolumn{3}{c}{ Frequências de colheita } & \multirow{2}{*}{ CV (\%) } & P-valor \\
\cline { 2 - 4 } & $90 \mathrm{IL}$ & $95 \mathrm{IL}$ & 28D & & \\
\hline Taxa de aparecimento de perfilhos (perfilhos.100perfilhos. dia $^{-1}$ ) & $0,58 \mathrm{a}$ & $0,47 \mathrm{ab}$ & $0,40 \mathrm{~b}$ & 18,23 & 0,049 \\
Taxa de mortalidade de perfilhos (perfilhos.100perfilhos.dia ${ }^{-1}$ ) & 0,31 & 0,21 & 0,21 & 28,85 & 0,110 \\
Taxa de sobrevivência de perfilhos (perfilhos.100perfilhos.dia- ${ }^{-1}$ ) & $0,67 \mathrm{~b}$ & $0,77 \mathrm{ab}$ & $0,80 \mathrm{a}$ & 8,15 & 0,043 \\
Balanço entre morte e aparecimento perfilhos & 0,27 & 0,26 & 0,19 & 37,31 & 0,410 \\
Índice de estabilidade & 1,06 & 1,17 & 1,09 & 8,62 & 0,300 \\
Densidade populacional de perfilhos (perfilhos. $\mathrm{m}^{-2}$ ) & 432,7 & 481,6 & 443,8 & 13,57 & 0,520 \\
\hline
\end{tabular}

${ }^{1} \mathrm{CV}$ : coeficiente de variação.

Massa de forragem, composição morfológica e acúmulo de forragem

Não se observou diferenças nas características MF, \%CV e \%FM, AF, TAF e TALF, sendo observada diferença apenas para a \%LF (Tabela 5). Maior \%LF foi observada na frequência 90IL $(81,5 \%)$ com menores valores sendo observados na frequência $28 \mathrm{D}$ de descanso $(72,32 \%)$. 
Tabela 5. Massa de forragem, porcentagem dos componentes morfológicos, acúmulo total e taxa de acúmulo de forragem de pastos de capim-sempre verde submetidos a frequências de colheita

\begin{tabular}{|c|c|c|c|c|c|}
\hline \multirow{2}{*}{ Variáveis } & \multicolumn{3}{|c|}{ Frequências de colheita } & \multirow{2}{*}{$\mathrm{CV}(\%)^{1}$} & \multirow{2}{*}{ P-valor } \\
\hline & 90IL & 95IL & $28 \mathrm{D}$ & & \\
\hline Massa de forragem $\left(\mathrm{kg} \cdot \mathrm{ha}^{-1}\right)$ & 2.416 & 3.015 & 3.063 & 22,2 & 0,27 \\
\hline Lâminas foliares (\%) & $81,5 \mathrm{a}$ & $79,2 a b$ & $72,3 b$ & 5,52 & 0,04 \\
\hline Colmo vivo $(\%)$ & 16,1 & 15,7 & 21,6 & 24,9 & 0,16 \\
\hline Forragem morta (\%) & 4,4 & 5,1 & 6,1 & 40,1 & 0,52 \\
\hline Acúmulo de forragem $\left(\mathrm{kg} \cdot \mathrm{ha}^{-1}\right)$ & 25.016 & 30.062 & 29.543 & 20,9 & 0,44 \\
\hline Taxa de acúmulo de forragem (kg.ha dia ${ }^{-1}$ ) & 141,9 & 138,9 & 110,7 & 23,7 & 0,33 \\
\hline Taxa de acúmulo de lâminas (kg.ha dia-1) & 98,9 & 91,3 & 78,0 & 19,73 & 0,30 \\
\hline
\end{tabular}

${ }^{1} \mathrm{CV}$ : coeficiente de variação.

\section{Correlações entre ambiente luminoso e estrutura do pasto}

Pode-se observar uma forte e positiva correlação entre a $A D$ e IL $\left(R^{2}=0,72\right)$ ou IAF $\left(R^{2}=0,81\right)$.

\section{DISCUSSÃO}

0 maior número de cortes, nos pastos manejados a 90IL, em relação a 95IL e 28D, é consequência da combinação da maior frequência (menores períodos de descanso) e de uma intensidade de corte menor ( $40 \%$ da $A D$ no PRC), fazendo com que diminua o tempo necessário para o pasto atingir novamente a condição PRC, resultando em um PD médio de 22,47 dias. Esse resultado corrobora com aqueles obtidos por Barbosa et al. (2007) e Zanine et al. (2011), ambos avaliando cultivares do gênero Megathrysus, os quais também observaram maior quantidade de ciclos nos tratamentos manejados com 90IL em comparação aos manejados com 95IL. A duração média do período de descanso do tratamento 95IL coincidiu com a do tratamento 28D. Contudo, esta condição pode ser alterada caso haja alterações nas condições climáticas (luminosidade, temperatura e pluviosidade) e de manejo (adubação, irrigação, altura de resíduo pós-pastejo). Isto indica maior eficiência dos sistemas que utilizam o emprego de períodos de descanso variados, os quais respeitam as respostas morfofisiológicas das plantas as condições climáticas e ao meio em que estão inseridas. Assim, permitese melhor desempenho na produção e na qualidade da forragem utilizada, contribuindo com 0 aumento da viabilidade de sistemas produtivos que utilizem forrageiras tropicais como fonte de alimento para produção pecuária, diferente de quando se adotam períodos fixos de descanso (Pedreira et al., 2007).
$A A D$ é consequência do tempo de rebrotação da gramínea e de suas adaptações morfológicas durante esse processo (Cutrim Júnior et al., 2011). Em gramíneas de crescimento cespitoso, como 0 capim Sempre-verde, os colmos são os principais responsáveis pela elevação da altura do dossel, durante a rebrotação, quando o período de descanso se prolonga demasiadamente (ultrapassa 95IL). Os pastos manejados na frequência 28D apresentaram maior $A D$, na condição PRC, provavelmente devido ao incremento de $37,5 \%$ na porcentagem dos colmos (Tabela 5). Pelo fato de o critério para definição da altura POC ter sido $40 \%$ da AD PRC, pastos com maior altura, como no tratamento 28D, já iniciavam a rebrotação mais altos $(63,19 \mathrm{~cm})$ fazendo com que $A D$ fosse se elevando a cada ciclo de colheita.

Durante a maior parte do período experimental, 0 capim-sempre-verde apresentou intenso florescimento, principalmente nas parcelas manejadas na frequência 28D e, em menor escala, nos manejados a 95IL. Esse florescimento pode ter contribuído com o aumento do alongamento dos colmos e, consequentemente, maior AD (Janusckiewicz et al., 2010). O florescimento pode ter contribuído não só com a elevação da $A D$, mas também fez com que a IL, entre as frequências de 95IL e 28D, no PRC, apresentassem-se como semelhantes (Tabela 2). Com o florescimento, há diminuição da densidade da forragem em estratos superiores do dossel, devido ao alongamento dos colmos, e aumento da distância dos entrenós do perfilho, permitindo que mais luz penetre no interior dossel, mesmo com o IAF elevado. Nos pastos manejados a 90IL é possível que a maior frequência de colheita tenha impedido os perfilhos de florescerem, sendo estes colhidos antes que houvesse diferenciação do meristema apical em inflorescência. 
Em culturas tropicais e provavelmente em culturas anuais que possuem na estrutura dos seus dosséis lâminas foliares senescentes e colmos em florescimento, estimativas do IAF (equipamentos) são comprometidas porque esses componentes da planta interceptam a luz incidente fazendo com que 0 equipamento superestime o IAF (Sbrissia e Da Silva, 2008). Nesse sentido, no tratamento 28D, além de apresentar porcentagem de lâminas foliares $9 \%$ inferior e taxa de acúmulo de lâminas $17 \%$ menor, há uma contribuição maior de porcentagem de colmos $(37,5 \%)$ e de forragem morta $(19,6 \%)$ na composição do IAF (Tabela 5) em comparação com o tratamento 95IL. Embora o tratamento 90IL tenha apresentado menor IAF POC, provavelmente esse IAF era composto por maior massa de lâminas foliares, o que proporciona rebrotação mais rápida, por interceptar luz logo após o corte, acarretando numa recuperação mais rápida dos carboidratos de reserva dos componentes da planta, como raízes e colmos (Donaghy e Fulkerson, 1998). Os efeitos positivos de um IAF residual maior, após o corte, podem ser melhor observados pelo maior NC e PD no tratamento 90IL em relação aos de 95IL e 28D (Tabela 3).

A maior TAP observada no tratamento 90IL é reflexo da maior frequência de corte, pois sabe-se que em pastos mais baixos (Tabela 2) é comum se observar maior renovação de perfilhos (Santos et al. 2010b; Silva et al. 2015). Esse padrão de resposta está relacionado com a diminuição da dominância apical dos perfilhos, reduzindo o sombreamento e permitindo que maior quantidade e qualidade de luz chegue à base das touceiras (Santos et al. 2010b; Taiz e Zeiger, 2004). Contrariamente a este padrão, o tratamento 28D apresentou menor TAP, estando relacionada com a maior $A D$ (aumento do sombreamento na base da planta) e com o intenso florescimento ocorrido nessa frequência, uma vez que a planta prioriza suas reservas orgânicas para a reprodução ao invés do aumento no número de perfilhos (Basso et al. 2010). Maior TAP normalmente resulta em maior TMP (Difante et al., 2008) como um mecanismo compensatório para manutenção do balanço de perfilhos considerando a disponibilidade de água e luz (Matthew et al., 2000). A maior TAP e TMP (ou menor TSP nesse caso) também há uma maior renovação de tecidos, levando a uma população mais jovem de perfilhos, podendo então gerar ganhos qualitativos (Sousa et al., 2019).
Diferenças no AF e TAF são esperadas entre manejos, desde o uso da AD como determinante da iniciação do pastejo, o que pode resultar em forragem colhida em condições fisiológicas semelhantes (Da Silva et al., 2015). Nesse sentido, Pedreira et al. (2009) submetendo o capim-xaraés a frequências de pastejo fixas e variáveis, também não observaram diferenças no AF e na proporção de alguns componentes morfológicos.

Desconsiderando-se efeitos das frequências no AF e considerando o valor em si, pode-se observar que, em comparação com trabalhos utilizando outras cultivares do mesmo gênero, pode-se afirmar que o capim Sempre-verde não fica muito abaixo, uma vez que seu AF variou de 25.016 a $30.062 \mathrm{~kg} \mathrm{ha}^{-1}$. Zanine et al., (2011), submetendo capim-tânzania a frequências de pastejo (90 ou $95 \%$ IL), registraram

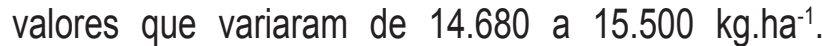
Silva et al. (2009) submetendo o capim-mombaça a diferentes frequências (95 ou 100\% IL) e intensidades (30 ou $50 \mathrm{~cm}$ de resíduo pós-pastejo) observaram que, de maneira geral, o AF foi em média $24.000 \mathrm{~kg} \mathrm{ha}^{-1}$. Isto demonstra que, em termos produtivos, o capim Sempre-verde pode ser utilizado em substituição às principais cultivares de Megathyrsus maximus, como Tanzânia e Mombaça.

Considerando o alto custo de medidores de luz a aplicação da interceptação luminosa no manejo do pastejo torna-se inviável para o produtor (Pedreira et al., 2017). Uma alternativa possível, para aplicar o conceito, seria estabelecer associações entre a interceptação luminosa e $A D$, uma vez a correlação entre essas variáveis é alta (King et al., 1986). Desse modo, traduzindo os resultados obtidos nesse experimento, para condições práticas do campo, podese afirmar que as $A D$, no PRC e POC, observadas para as frequências $90 \mathrm{IL}(80 / 48 \mathrm{~cm})$ e $95 \mathrm{IL}(85 / 52 \mathrm{~cm})$ podem ser utilizadas para interromper a rebrotação e 0 pastejo, respectivamente.

A utilização da frequência de colheita variável é mais efetiva em controlar a estrutura do dossel que a fixa, além de proporcionar foragem de composição morfológica mais adequada ao consumo animal e perfil mais jovem da população de perfilhos. 0 capim sempre-verde pode ter sua rebrotação interrompida quando o dossel atingir entre $80-85 \mathrm{~cm}$ de altura e 0 pastejo encerrado quando atingir $50 \mathrm{~cm}$. 
Figura 1. Correlação entre interceptação luminosa e altura do dossel (esquerda) ou índice de área foliar e altura do dossel (esquerda) de pastos de capim-sempre verde submetidos a frequências de colheita

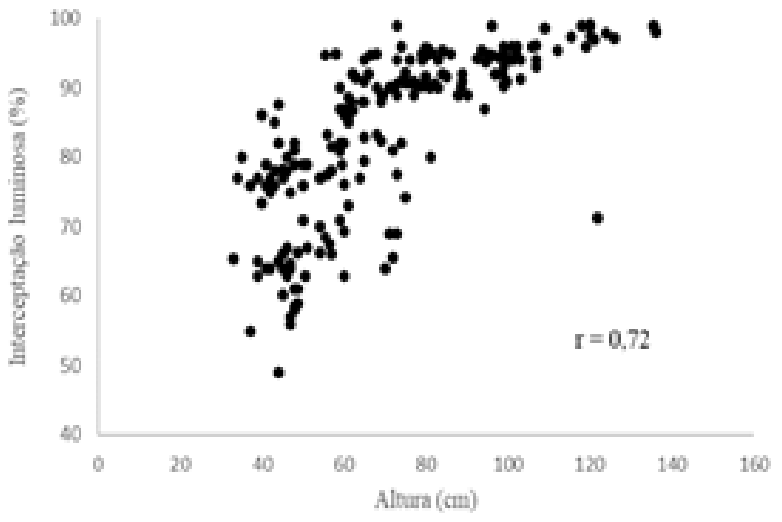

\section{REFERÊNCIAS BIBLIOGRÁFICAS}

Barbosa, R.A.; Nascimento Júnior, D.; Euclides, V. P. B.; Da Silva, S. C.; Zimmer, A. H.; Torres Júnior, R. A. A. Capim-tanzânia submetido a combinações entre intensidade e frequência de pastejo. Pesquisa Agropecuária Brasileira, 2007, 42, 329-340.

Barthram, G.T. Experimental techniques: the HFRO sward stick. In: ALCOCK, M.M. (Ed.) Biennial Report of the Hill Farming Research Organization. Midlothian: Hill Farming Research Organization, 1985, 29-30.

Basso, C. K.; Cecato, U.; Lugão, S. M. B.; Gomes, J. A. N.; Barbero, L. M.; Mourão, G. B. Morfogênese e dinâmica do perfilhamento em pastos de Panicum maximum Jacq. Cv. IPR-86 Milênio submetido a doses de nitrogênio. Revista Brasileira de Saúde e Produção Animal, 2010, 11, 4, 976-989.

Carnevalli, R. A.; Da Silva, S. C.; Bueno, A. A. O.; Uebele, M. C.; Bueno, F. O.; Hodgson, J.; Silva, G. N.; Morais, J. P. G. Herbage production and grazing losses in Panicum maximum cv. Mombaça under four grazing managements. Tropical Grasslands, 2006, 40, 165-176.

Cutrim Junior, J. A. A.; Cândido, M. J. D.; Valente, B. S. M.; Carneiro, M. S. S.; Carneiro, H. A. V. Características estruturais do dossel de capimtanzânia submetido a três frequências de desfolhação e dois resíduos póspastejo. Revista Brasileira e Zootecnia, 2011, 40, 489497.

Da Silva, S. C.; Pereira, L. E. T.; Sbrissia, A. F.; Hernandez-Garay, A. Carbon and nitrogen reserves in marandu palisade grass subjected to intensities

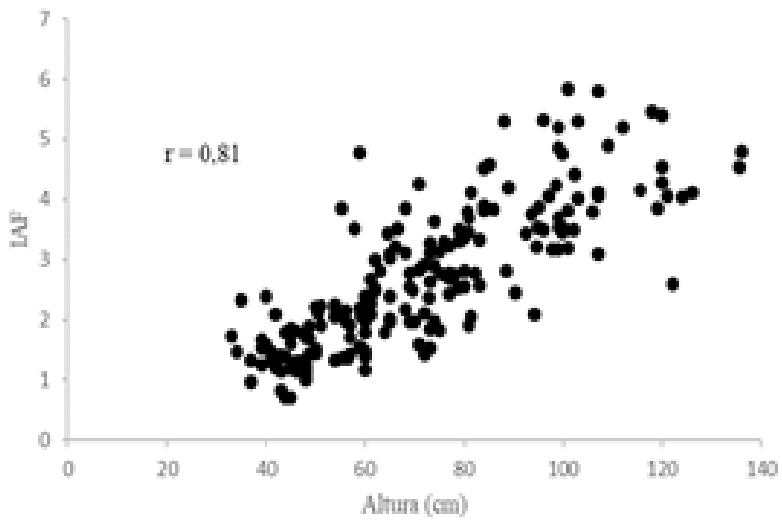

of continuous stocking management. Journal of Agricultural Science, 2015, 153, 1449-1463.

Da Silva, S. C.; Nascimento Jr., D. Avanços na pesquisa com plantas forrageiras tropicais em pastagens: características morfofisiológicas e manejo do pastejo. In: REUNIÃO ANUAL DA SOCIEDADE BRASILEIRA DE ZOOTECNIA, 44., Lavras. Anais... Lavras, MG: SBZ, 2007. p. 121- 138, 2007.

Difante, G. S.; Nascimento Júnior, D.; Da Silva, S. C.; Euclides, V. P. B.; Zanine, A. M.; Adese, B. Dinâmica do perfilhamento do capim-marandú cultivado em duas alturas e três intervalos de corte. Revista Brasileira de Zootecnia, 2008, 37, 2, 189-196.

Donaghy, D.J.; Fulkerson, W.J. Priority for allocation of water-soluble carbohydrate reserves during regrowth of Lolium perenne. Grass and Forage Science, 1998, 53, 3, 211-218.

Fonseca, L.; Mezzalira, J. C.; Bremm, C.; Filho, R. S. A.; Gonda, H. L.; Carvalho, P. C. F. Management targets for maximizing the short-term herbage intake rate of cattle grazing in Sorghum bicolor. Livestock Science, 2012, 145, 205-211.

Jank, L.; Martuscello, J. A.; Euclides, V. B. P.; Valle, C. B.; Resende, R. M. S. Panicum maximum. In: Fonseca, D.M.; Martuscello, J.A. (Ed.). Plantas forrageiras, 2010, 166196.

Janusckiewicz, E. R.; Magalhães, M. A.; Ruggieri, A. C.; Reis, R.A.; Massa de forragem, composição morfológica e química do capim-Tanzânia sob diferentes dias de 
descanso e resíduos pós-pastejo. BioScience Journal, 2010, 26, 2, 161-172.

Macedo, C. H. O.; Alexandrino, E.; Jakelaitis, A.; Vaz, R. G. M. V.; Reis, R. H. P.; Vendrusculo, J. Características agronômicas, morfogênicas e estruturais do capim Panicum maximum cv. Mombaça sob desfolhação intermitente. Revista Brasileira de Saúde Produção Animal, 2010, 11, 4, 941-952.

Matthew, C.; Assuero, S.G.; Black, C.K.; Sackville Hamilton, H. C. Tiller dynamics of grazed swards. In: Lemaire, G.; Hodgson, J.; Moraes, A.; Carvalho, P.C.F.; Nabinger, C. (Eds.) Grassland ecophysiology and grazing ecology, Wallingford: CABI Publishing, 2000, 127-150.

Pedreira, B.C.; Pedreira, C.G.S.; Da Silva, S.C. Estrutura do dossel e acúmulo de forragem de Brachiaria brizantha cultivar Xaraés em resposta a estratégias de pastejo. Pesquisa Agropecuária Brasileira, 2007, 42, 2, 281-287.

Pedreira, B. C.; Pedreira, C. G. S.; Da Silva, S. C. Acúmulo de forragem durante a rebrotação do capimxaraés submetido a três estratégias de desfolhacão. Revista Brasileira de Zootecnia, 2009, 38, 618-625.

Pedreira, C. G. S.; Braga, G. J.; Portela, J. N. Herbage accumulation, plant-part composition and nutritive value on grazed signal grass (Brachiaria decumbens) pastures in response to stubble height and rest period based on canopy light interception. Crop \& Pasture Science, 2017, 68, 62-73.

Pompeu, R.C.F.F.; Cândido, M. J. D.; Neiva, J. N. M.; Rogério, M. C. P.; Benevides, Y. I.; Oliveira, B. C. M. Fluxo de biomassa em capim-tanzânia sob lotação rotativa com quatro níveis de suplementação concentrada. Revista Brasileira Zootecnia, 2009, 38, 5, 809-817.
Santos, M. E. R.; Fonseca, D. M.; Balbino, E. M.; Silva, S. P.; Monnerat, J. P. I. S. Valor nutritivo de perfilhos e componentes morfológicos em pastos de capimbraquiária diferidos e adubados com nitrogênio. Revista Brasileira de Zootecnia, 2010, 39, 1919-1927.

Sbrissia, A. F.; Da Silva, S. C. Compensação tamanho/ densidade populacional de perfilhos em pastos de capim-marandu. Revista Brasileira de Zootecnia, 2008, $37,1,35-47$.

Silva, L. V.; Cândido, M. J. D.; Pessoa, J. P. M.; Cavalcante, A. C. R.; Carneiro, M. S. S.; Silva, A. N. Componentes da biomassa e características estruturais em capim-aruana sob diferentes frequências $e$ intensidades de desfolhação. Pesquisa Agropecuária Brasileira, 2015, 50, 12, 1192-1200.

Silva, S. C.; Bueno, A. A. O.; Carnevalli, R. A.; Uebele, M. C.; Bueno, F. O.; Hodgson, J.; Matthew, C.; Arnold, G. C.; Morais, J. P. G. Sward structural characteristics and herbage accumulation of Panicum maximum cv. Mombaça subjected to rotational stocking managements. Scientia Agricola, 2009, 66, 819.

Sousa, B. M. L.; Rizato, C. A.; Fagundes, J. L.; Fontes, P. T. N.; Backes, A. A.; Oliveira Júnior, L. F. G.; Cruz, N. T.; Nascimento, C. S. Tillering dynamics of digit grass subjected to different defoliation frequencies. Pesquisa Agropecuária Brasileira, 2019, 54, e00668.

Taiz, L.; Zeiger, E. Fisiologia Vegetal. Porto Alegre: Artmed, 3 ed., 719p. 2004.

Zanine, A. M.; Nascimento Jr., D.; Santos, M. E. R.; Pena, K. S.; Da Silva, S. C.; Sbrissia, A. F. Características estruturais e acúmulo de forragem em capim-tanzânia sob pastejo rotativo. Revista Brasileira de Zootecnia, 2011, 40, 2364-2373. 